\title{
Analyses of the effectiveness of a Brazilian pediatric home care service: a preliminary study
}

\author{
Antônio José Lana de Carvalho', Hyster Martins Ferreira', Eliza Fernanda Borges', Laerte Honorato Borges Junior², \\ Ana Laura Teodoro de Paula ${ }^{3}$, Wallisen Tadashi Hattori ${ }^{4}$ and e Vivian Mara Gonçalves de Oliveira Azevedo ${ }^{5^{*}}$ (D)
}

\begin{abstract}
Background: Technological advances in health care currently provide better care conditions and have increased survival rates of premature infants, along with increasing the life expectancy of chronically ill children. In this context, the home care service has emerged as an effective tool for the treatment of this group of children. Thus, this preliminary study aimed at evaluating the effectiveness of the Home Care Service (HCS) with regard to pediatric care.

Methods: A cross-sectional study was performed through a medical record analysis of a tertiary hospital in Minas Gerais/ Brazil. Two groups were compared: 36 patients from the HCS (home group) and 13 patients hospitalized with an indication for home care (hospital group). To analyze the effectiveness of HCS, we evaluated the number of readmissions, infection rate, number of procedures, and optimization of beds.

Results: The hospital group presented 6.04 times more infections and was submitted to 6.43 times more procedures. The home group presented lower readmission rates; with $41.66 \%$ of children studied not being readmitted and $76.19 \%$ of those who needed readmissions did so after more than 30 days from hospital discharge. HCS optimized hospital beds and allowed, over five (5) years, the hospitalization of around 102 patients in the hospital studied.

Conclusion: In this preliminary study, HCS reduced the number of procedures and infections compared to hospitalized patients. Moreover, HCS presented lower readmission rates and optimized hospital beds, which could be considered an indication of effectiveness.
\end{abstract}

Keywords: Home care, Health service effectiveness, Chronic disease

\section{Background}

Technological advances in the treatment of health problems over recent years have provided better care conditions and increased survival of prematurely born children, as well as an increase in life expectancy and a decrease in child mortality [1], which provides an improvement to chronic health conditions throughout the world [2].

However, we conceptualized children with chronic health conditions of up to 1 year as a limiting and evolving condition, characterized by loss of locomotion capacity and loss

\footnotetext{
* Correspondence: viviangazevedo1@gmail.com

${ }^{5}$ Faculty of Physical Education and Physical Therapy, Federal University of Uberlândia, 1286 - Benjamin Constant St., Nossa Sra. Aparecida, Uberlândia 38400-678, Brazil

Full list of author information is available at the end of the article
}

of social relationships. In addition to the need for technological devices, the use of controlled and continuous medications, with gastrointestinal problems, mainly related to deglutition; psychological and cognitive alterations, dependent on neuropsychomotor stimulation, in addition to specialized educational and health services [3].

Several countries have tried to adapt to this new demand for offered care, due in particular to issues of economic viability [4]. This has strengthened the emergence of new strategies and mechanisms for health care, such as Home Care Services (HCS), which combines technological and scientific resources present in the hospital with the family environment [5]. The domicile, owing to its humanizing characteristic and the demographic and

(c) The Author(s). 2019 Open Access This article is distributed under the terms of the Creative Commons Attribution 4.0 International License (http://creativecommons.org/licenses/by/4.0/), which permits unrestricted use, distribution, and reproduction in any medium, provided you give appropriate credit to the original author(s) and the source, provide a link to the Creative Commons license, and indicate if changes were made. The Creative Commons Public Domain Dedication waiver (http://creativecommons.org/publicdomain/zero/1.0/) applies to the data made available in this article, unless otherwise stated. 
epidemiological profile of the population, is a place with potential to expand and qualify care processes [6].

The development of HCS around the world has been accompanied by demographic and epidemiological changes [7] and is related to reduction of risks of infections [8], humanization of care and quality of life, greater involvement of relatives with patient disease, tightening of health staff/patient/family relationship [9], reduction of costs, increased turnover of hospital beds with bed management, de-hospitalization [10], lower rates of clinical worsening and acute complications, lower demand for emergency and emergency services, lower rates of re-hospitalization [11], implementation of palliative care [12] and effective prevention, promotion and recovery of health actions [13].

Despite the expansion of HSC in several countries, there is still a need to investigate whether this type of service is as effective as the service provided in the hospital environment, this was performed using four primary variables: quantitative infections, number of readmissions, optimization of hospital beds and the number of procedures [8]. Therefore, this study had as its objective to evaluate the effectiveness of a Home Care Service, regarding pediatrics care $[7,14]$.

\section{Methods}

\section{Population}

This preliminary study included 57 pediatric patients with chronic health conditions, restricted socialization and limited contact with the external environment, low mobility, frequent exacerbations and locomotion restrictions, as well as belonging to type 2 ( $\mathrm{HC} 2)$ and type 3 (HC3) home care.

In Brazil, there are three types of home care: $\mathrm{HC}$, $\mathrm{HC} 2$ and HC3. The HC1 modality is composed of children who require minimal and less frequent multiprofessional interventions, who have health problems compensated by receiving care through their caregivers, and their health supervision is carried out by Basic Health Units (BHU) [15].

In the $\mathrm{HC} 2$ modality, patients with acute or chronic acute degenerative diseases are included, and who require constant and continuous care. They could be premature or of low weight, undergoing drug and non-parenteral infusion or in palliative care. In the HC3 modality, they present the same clinical conditions identified for the HC2 modality, but require continuous multiprofessional supervision, requiring mechanical ventilation, performing complex procedures, parenteral nutrition and blood transfusion, demanding constant home monitoring [16].

Patients were divided into two groups for comparison and the effectiveness analysis:

\section{Hospital group}

The hospital group comprised of the convenience analysis containing 13 patients, that is all children with an indication for home care, since the beginning of the first indication of hospital discharge for home care maintenance in the institution where this study was carried out (from 2007 to 2016). For some reason they remained in the hospital for more than 30 days after the indication for home care service because of a social context or to finalize the training of home caregivers. This indication for hospital discharge was identified from health professional records, which indicated hospital discharge and continuation of home care, and the date of the discharge report was the beginning of the data collection process until the clinical outcome, transfer and consequential admission to the HCS.

\section{Home group}

A total of $36 \mathrm{HCS}$-assisted children were selected over the 5-year interval (January 01, 2012 to December 31, 2016). Patients with a home care interval of less than 30 days were excluded in order to match the minimum adopted care interval as a criterion in the hospital sample (Fig. 1).

Figure 1 Number of patients included and excluded in the study and their respective groups.

Concerning the 49 children included in this study, 36 were assisted through HCS and 13 through the hospital service. The characteristics of the evaluated population are presented on Table 1 .

Table 1 Sample characteristics: patients in home care and patients hospitalized. Brazil, 2012-2016.

\section{Procedure}

The study was designed as a cross-sectional study. The collection and selection of medical records were performed in both the medical records and inactive files, analyzing all pediatric patients aged between 29 days and 11 years, 11 months and 29 days of age. This was seen as an adequate age range for admission to the pediatric ward of a tertiary level university hospital and into the HCS program of the same institution [15].

Data collection was performed using a spreadsheet structured from a table of indicators that contained four main variables for the evaluation of HCS effectiveness: readmissions, number of infections, optimization of hospital beds and procedures performed (laboratory and imaging examinations).

We analyzed epidemiological profiles, degree of dependence, classification of the type of care ( $\mathrm{HC} 2$ and $\mathrm{HC} 3$ ), main diagnosis, care category (neuromuscular disease, genetic syndrome, pulmonary disease, cerebral palsy, spinal cord injuries and others), need for mechanical ventilation or device used.

For the analysis of effectiveness, the study contemplated the pairing of the two groups, and the observations made in the first group were paired with those of the second, guaranteeing an equivalent composition. 


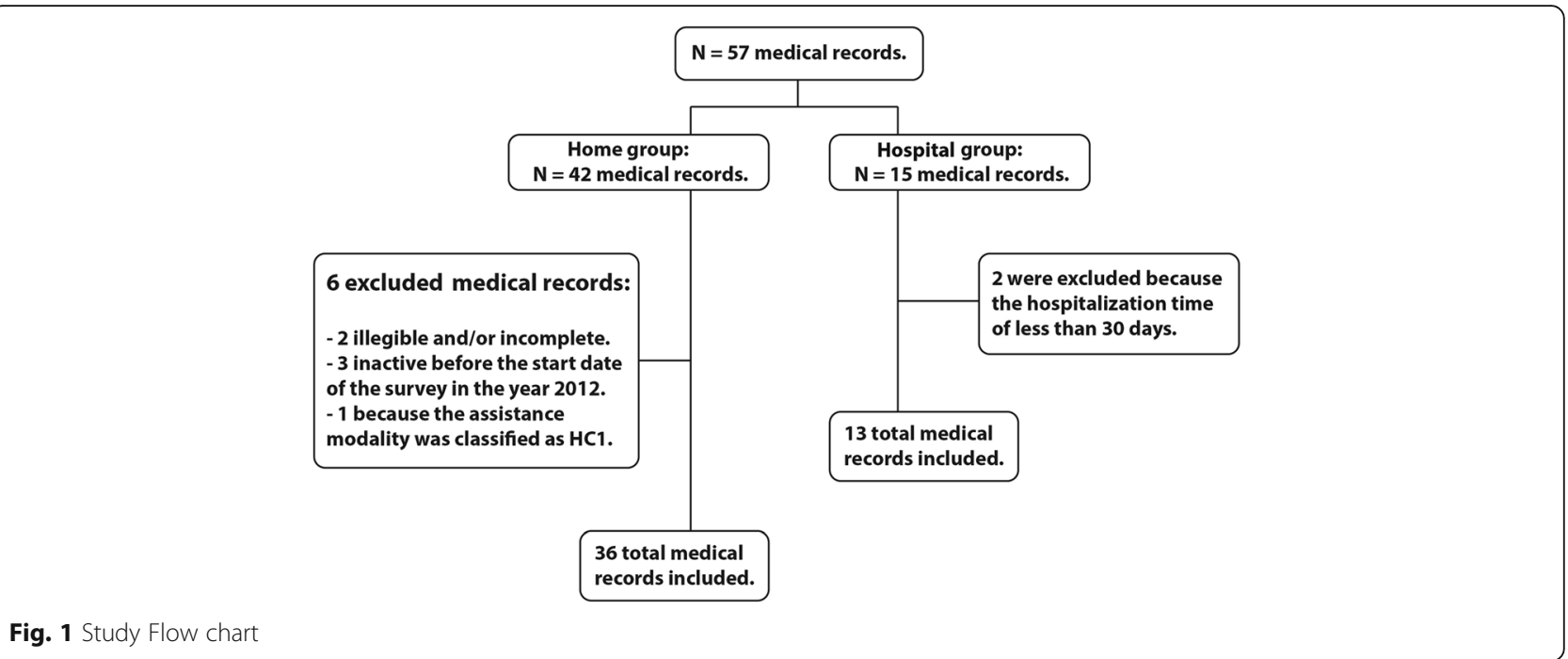

Concerning the number of procedures, we analyzed all laboratory and imaging exams performed during the study period. Among the laboratory tests, the most notable are urine exams (Abnormalities of urinary sediment and urine culture), blood tests (blood culture, biochemistry, venous and arterial blood gas analysis, Troponin Activity Time (TAP) and central venous catheter aspiration), tracheal secretion, central venous catheter tip, ocular secretion swabs and wounds, faeces (parasitological and coproculture), aspirate liquid acetic (cytological and culture of peritoneal fluid). In addition to the aforementioned examinations, imaging exams were performed, those being $\mathrm{x}$-ray, electrocardiograms, echocardiograms and ultrasonography.

\section{Data analysis}

Descriptive analyzes were carried out with the use of absolute frequency and percentage for categorical and ordinal variables, maximum and minimum values and mean for metric variables. Infection rates, bed optimization, re-hospitalization and procedures were calculated considering the total number of records divided by the total number of days of hospitalization (home or hospital) of each group. Thus, the rate found did not depend on the number of participants in each sample, but on the occurrence of these events within their respective groups.

This study was approved by the Ethics Committee on Human Research of the Federal University of Uberlândia (approval number: 1823938).

\section{Results}

For the analysis of readmissions, we verified how many days after the date of admission into the HCS these patients were submitted to the first hospital readmission, in a time interval before and after 30 days [16]. We also took as a reference the total number of days of rehospitalization (Table 2).
Infection, outcome and procedure rates were calculated considering the total number of records divided by the total number of days of hospitalization (home or hospital) of each group. Thus, the rate found did not depend on the number of participants in each sample, but on the occurrence of these events within their respective groups (Table 3).

Table 3 Comparative analysis of procedures, infections, days of hospitalization and clinical outcome. Brazil, 2012-2016.

Regarding the optimization of beds, the following analysis and subsequent calculation were used in order to verify the sum of the total days of hospitalization of home group patients, between 01/01/2012 and 12/31/ 2016. There were found to be 31,922 days of hospitalization in this service; this number divided by the average number of hospitalization days per patient in the pediatric ward, arrives at 9.80 days (Source: Hospital information management and statistical sector). Thus, we reached 3257.35 days available for HCS. By dividing this number (3257.35 days) by the number of active beds ( 32 beds) in the pediatric unit, it would be possible, over five (5) years, to hospitalize around 102 patients in the hospital studied.

\section{Discussion}

In order to evaluate the effectiveness of a Home Care Service, comparative and equivalent to that offered by in-hospital service, from four variables, those being the number of infections, the number of readmissions, the optimization of hospital beds and the number of hospitalizations procedures. The study showed that HCS has low infection rates, procedures and readmissions, while optimizing hospital beds, which all can be considered as an indication of its effectiveness.

Regarding the number of infections, the hospital group presented an infection rate 6.04 times higher than the 
Table 1 Sample characteristics: Patients in home care assisted by a home care service (HCS) and patients hospitalized in a hospital service. Brazil, 2012-2016

\begin{tabular}{|c|c|c|c|}
\hline \multirow[t]{2}{*}{ Variables } & \multicolumn{2}{|c|}{$\begin{array}{l}\text { Modality of assistance } \\
(\mathrm{n} / \%)\end{array}$} & \multirow[t]{2}{*}{$\begin{array}{l}p- \\
\text { value }\end{array}$} \\
\hline & $\begin{array}{l}\text { Home group } \\
n=36)\end{array}$ & $\begin{array}{l}\text { Hospital group } \\
(n=13)\end{array}$ & \\
\hline$\overline{S e x^{a}}$ & & & 0.989 \\
\hline Male & $25 / 30.56$ & $9 / 69.23$ & \\
\hline Female & $11 / 69.44$ & $4 / 30.77$ & \\
\hline Dependence degree ${ }^{b}$ & & & 0.561 \\
\hline Wanders & $2 / 5.56$ & $1 / 7.60$ & \\
\hline Wheelchair user & $1 / 2.78$ & $1 / 7.69$ & \\
\hline Bedridden & $33 / 91.67$ & $11 / 84.62$ & \\
\hline Classification by type of care ${ }^{b}$ & & & 0.663 \\
\hline $\mathrm{HC2}$ & $7 / 19.44$ & $1 / 7.69$ & \\
\hline $\mathrm{HC} 3$ & $29 / 8.56$ & $12 / 92.31$ & \\
\hline Medical devices ${ }^{c}$ & & & - \\
\hline Oxygen therapy & $9 / 25.00$ & $8 / 61.5$ & \\
\hline$I M V^{d}$ & $19 / 52.78$ & $9 / 69.2$ & \\
\hline IMV Intermittent & $8 / 22.22$ & $3 / 23.0$ & \\
\hline NIMV ${ }^{d}$ & $0 / 0.00$ & $0 / 0.00$ & \\
\hline NIMV Intermittent & $2 / 5.56$ & $0 / 0.00$ & \\
\hline GTM & $31 / 86.11$ & $12 / 92.3$ & \\
\hline PVC & $0 / 0.00$ & $1 / 7.69$ & \\
\hline Tracheostomy & $27 / 75.00$ & $10 / 76.9$ & \\
\hline Colostomy & $1 / 2.78$ & $1 / 7.69$ & \\
\hline Tenckoff catheter & $1 / 2.78$ & $1 / 7.69$ & \\
\hline Main Diagnosis ${ }^{c}$ & & & - \\
\hline Pulmonary disease & $4 / 11.11$ & $0 / 0.00$ & \\
\hline Neurological disease & $16 / 44.44$ & $7 / 53.85$ & \\
\hline Genetic syndrome & $12 / 33.33$ & $2 / 15.38$ & \\
\hline Others & $4 / 11.11$ & $4 / 30.77$ & \\
\hline Age Group ${ }^{b}$ & & & 0.465 \\
\hline Infants (29 days to 12 months) & $13 / 38.2$ & $2 / 15.38$ & \\
\hline Toddlers ( 1 to 3 years old) & $14 / 41.2$ & $6 / 46.15$ & \\
\hline Kindergarten children ( 4 to 5 years old) & $3 / 8.8$ & $1 / 7.69$ & \\
\hline School children (6 to 12 years old) & $6 / 17.6$ & $4 / 30.77$ & \\
\hline
\end{tabular}

HC2 Home care type 2, HC3 Home care type 3, IMV Invasive mechanical ventilation, NIMV Noninvasive mechanical ventilation, GTM Gastrostomy, PVC Permanent venous catheter

${ }^{a}$ Chi-square Independence test applied to the variable and Modality of assistance

${ }^{b}$ Fisher Exact test applied to the variable and Modality of assistance

${ }^{c}$ No statistical association was possible due low frequency in some categories

${ }^{d}$ continuous use

home group. A study carried out in a French university hospital showed that infections were the main cause of death in hospitalized patients [17]. The length of hospital stay is a contributing factor for occurrence of infections related to hospital or nosocomial resistance [18]. A review conducted in 2014 found that antimicrobial resistance could cause the death of up to 10 million people per year by 2050 [19]. Indeed, measures for prevention of Health Care Related Infections (HCRI) should be adopted in all health care settings, either in the hospital setting, in chronic care facilities or in home care, in light of this growing threat to global public health [20].

In order to verify optimization of hospital beds, according to the calculation demonstrated previously. HCS 
Table 2 Occurrences of hospital readmissions (exclusive to the home group), assisted by a Home Care Service. Brazil, $2012-2016$

\begin{tabular}{|c|c|}
\hline Hospital readmissions & $\begin{array}{l}\text { Home group }(n=36) \\
\mathrm{n} / \%\end{array}$ \\
\hline Patients who never were re-hospitalized & $15 / 41.66$ \\
\hline Patients re-hospitalized & $21 / 58.33$ \\
\hline First readmission, between 10 and 30 days after admission to HCS & $5 / 23.81$ \\
\hline Readmission after 30 days of admission in HCS & $16 / 76.19$ \\
\hline Readmission after 3 months after admission in HCS & $13 / 24.07$ \\
\hline Total days in readmission/total days in HCS & $930 / 2.91$ \\
\hline
\end{tabular}

55 cases of readmissions for 36 patients included. Average of 11.92 days of readmission for a total of 930 days

stands out for its contribution to the optimization of hospital beds. It is an effective care tool that contributes to reducing the need for the hospitalization of patients with high utilization rates of hospital services [21].

Regarding the procedures, the results showed that patients in the hospital group were submitted to 6.43 times more procedures than patients from the home group in the same time interval, this result is very similar to the infection rate. In fact, in recent decades, public expenditures on health has increased exponentially, mainly due to the excess number of laboratory and radiographic examinations requested by doctors, performed in an inadequate and/or unnecessary way [22]. Since 1998, 95\% of the examinations performed are repetitively requested, and as such contribute to increasing the cost of care for patients admitted to hospitals [23]. Although the tests are useful for diagnosis, it is necessary to consider the high financial cost involved for health services [24]. According to an English systematic review, with 109 articles aimed at reducing the use of laboratory tests by physicians, showed that educational measures were more effective when it came to reducing their use [25]. In Brazil, the Ministry of Health did not set a limit for exams [26]. In light of the aforementioned, one notes that HCS is a promising instrument in terms of the reduction of health costs, when referring to the relevance of procedures.

Table 3 Number of procedures (laboratory tests and imaging tests), number of infections, days of hospitalization and clinical outcome of patients in home care. Brazil, 2012-2016

\begin{tabular}{|c|c|c|c|c|}
\hline \multirow[t]{2}{*}{ Variables } & \multicolumn{4}{|l|}{ Modality of assistance } \\
\hline & Home group $(n=36)$ & medium (máx/mín) & Hospital group $(n=13)$ & medium (máx/mín) \\
\hline \multicolumn{5}{|l|}{ Number of Procedures } \\
\hline Total & 432 & $9(56 / 1)$ & 228 & $12(61 / 3)$ \\
\hline Laboratory & 367 & $7(52 / 1)$ & 211 & $12(60 / 2)$ \\
\hline Imaging & 65 & $1(10 / 1)$ & 17 & $1(5 / 1)$ \\
\hline No. of procedures / day & 0.014 & - & 0.09 & - \\
\hline No. of procedures / 30 days & 0.40 & - & 2.8 & - \\
\hline No. of procedures / 60 days & 0.80 & - & 5.6 & - \\
\hline \multicolumn{5}{|l|}{ Infections } \\
\hline Yes (n/\%) & $17 / 28.33$ & - & $37 / 90.24$ & - \\
\hline Total no. of infections per patient & 0.47 & - & 2.84 & - \\
\hline No. of infections per day & 0.0005 & - & 0.01 & - \\
\hline No. of infections for 30 days & 0.016 & - & 0.4 & - \\
\hline No. of infections for 60 days & 0.03 & - & 0.8 & - \\
\hline Total days in hospital & 31.922 & 656 & 2630 & 104.50 \\
\hline \multicolumn{5}{|l|}{ Outcome } \\
\hline Remains in hospital (n/\%) & $21 / 58.33$ & - & $13 / 100$ & - \\
\hline Clinical discharge (n/\%) & $5 / 13.89$ & - & $0 / 0.00$ & - \\
\hline Hospital death (n/\%) & $9 / 25.00$ & - & $0 / 0.00$ & - \\
\hline Home death (n/\%) & $2 / 5.56$ & - & $0 / 0.00$ & - \\
\hline Administrative discharge (n/\%) & $1 / 2.78$ & - & $0 / 0.00$ & - \\
\hline
\end{tabular}


In terms of the 36 home care patients who participated in this study, 15 (41.66\%) were never re-hospitalized and $21(58.33 \%)$ had one or more readmissions, and 5 patients returned to the hospital within 10 to 30 days (23.81\%), 16 patients after 30 days (76.19\%) and 13 after 3 months (24.07\%) from the date of hospital discharge. We point out that all re-hospitalizations occurred in the same reference hospital for the care of these patients, according to an agreement made between the Public Prosecutor's Office, family members and the health institution, during the process of de-hospitalization. In 2002, a Spanish study identified low readmission rates of 10, 28 days, and 3 months of 3.6, 9.7 and $13.5 \%$, respectively [27]. In fact, hospital readmissions are a frequent problem in health institutions. They are also an indicator of quality of care, based on the analysis of people admitted for the first time to the hospital within 30 days after discharge [16]. This indicator assesses the progressive capacity of the service provider in terms of helping patient recovery to happen as effectively as possible, with regard to patient care after hospital discharge [28]. In fact, there is a dearth of data in medical literature for the evaluation of early hospital readmissions in pediatrics with a specific focus on home care.

The study, however, contains limitations for its retrospective treatment and data collection, both performed through the analysis of medical records, which at times present incomplete and/or illegible records. As HCS has recent legal norms for implementation and regulation, there are few studies regarding the effectiveness of HCS in Brazil, addressing pediatric patients. Another complicating factor is the lack of parameters for analysis, where the quantity of exams is considered to be in excess, since the Ministry of Health does not establish any normative indication.

\section{Conclusions}

This preliminary study showed that HCS-assisted patients underwent fewer procedures and demonstrated a significant reduction in their use, in addition to a low number of infections compared to hospitalized patients. Moreover, HCS presented lower readmissions rates and optimized hospital beds, which could be considered an indication of effectiveness.

\section{Abbreviations}

BHU: Basic Health Units; GTM: Gastrostomy; HC1: Home Care type 1; HC2: Home Care type 2; HC3: Home Care type 3; HCRl: Health Care Related Infections; HCS: Home Care Service; IMV: Invasive Mechanical Ventilation; NIMV: Noninvasive mechanical ventilation; PVC: Permanent venous catheter; TAP: Troponin Activity Time

\section{Acknowledgements}

The authors thank all partners for contributing in the development of this article, especially the Hospital of Clinics of Uberlândia of the Federal University of Uberlândia, an institution of tertiary level and of national reputation, as far as the Home Care Service is concerned, besides being among the five federal hospitals with greater productivity in Brazil.
Funding

No funding given.

\section{Availability of data and materials}

The datasets used and/or analysed during the current study are available from the corresponding author on reasonable request.

\section{Authors' contributions}

AJLC, HMF, VMGOA and LHBJ conceived and designed the study. AJLC, WTH, ALTP and EFB performed data collection. AJLC, WTH and VMGOA supervised data analysis. All authors (AJLC, HMF, LHBJ, EFB, ALTP, WTH, VMGOA)

contributed to interpreting and discussing the results, writing and reviewing the manuscript. All authors read and approved the final manuscript.

\section{Ethics approval and consent to participate}

This study was approved by the Research Ethics Committee of the Federal University of Uberlândia (number of approval: 1823938). The informed consent was deemed unnecessary due to retrospective nature of this study.

\section{Consent for publication}

Not applicable.

\section{Competing interests}

The authors declare that they have no competing interests.

\section{Publisher's Note}

Springer Nature remains neutral with regard to jurisdictional claims in published maps and institutional affiliations.

\section{Author details}

${ }^{1}$ Graduate Program in Health Science, Faculty of Medicine, Federal University of Uberlândia, 1720 - Pará Ave., Umuarama, Uberlândia 38405-320, Brazil. ${ }^{2}$ Home Care Service, Hospital of Clinics of Uberlândia, Federal University of Uberlândia, 1720 - Pará Ave, Umuarama, Uberlândia 38405-320, Brazil. ${ }^{3}$ Institutional Program for Voluntary Scientific Initiation, Medical School, Federal University of Uberlândia, 1720 - Pará Ave., Bloco 2U, Umuarama, Uberlândia 38402-022, Brazil. ${ }^{4}$ Department of Public Health, Faculty of Medicine, Federal University of Uberlândia, 1720 - Pará Ave., Umuarama, Uberlândia 38405-320, Brazil. ${ }^{5}$ Faculty of Physical Education and Physical Therapy, Federal University of Uberlândia, 1286 - Benjamin Constant St., Nossa Sra. Aparecida, Uberlândia 38400-678, Brazil.

Received: 7 January 2019 Accepted: 8 May 2019

Published online: 22 May 2019

References

1. Berry JG, Agrawal R, Kuo DZ, et al. Characteristics of hospitalizations for patients who use a structured clinical care program for children with medical complexity. J Pediatr. 2011;159(2):284-90.

2. Saigal S, Stoskopf B, Streiner D, et al. Transition of extremely low-birthweight infants from adolescence to young adulthood: comparison with normal birth-weight controls. Jama. 2006;295(6):667-75.

3. RK S. The 1990s: A decade of change in understanding children with ongoing conditions. Arch Pediatr Adolesc Med. 2011;165(10):880-3 https:// doi.org/10.1001/archpediatrics.2011.165.

4. de OLL, Gonçalves A de C, da CJSD, Bonilha AL de L. Maternal and neonatal factors related to prematurity. Rev da Esc Enferm da USP. 2016:50:382-9.

5. Shepperd S, lliffe S, Doll HA, et al. Admission avoidance hospital at home. Cochrane Database Syst Rev. 2016;1(9):1-67.

6. Pouw MA, Calf AH, van Munster BC, ter Maaten JC, Smidt N, de Rooij SE. Hospital at Home care for older patients with cognitive impairment: a protocol for a randomised controlled feasibility trial. BMJ Open. 2018;8(3): e020332.

7. Genet N, Boerma WGW, Kringos DS, et al. Home care in Europe: a systematic literature review. BMC Health Serv Res. 2011;11(1):207. https://doi. org/10.1186/1472-6963-11-207.

8. Low LL, Vasanwala FF, Ng LB, Chen C, Lee KH, Tan SY. Effectiveness of a transitional home care program in reducing acute hospital utilization: a quasi-experimental study. BMC Health Serv Res. 2015;15(1):100. 
9. Voudris KV, Silver MA. Home hospitalization for acute decompensated heart failure: opportunities and strategies for improved health outcomes. Healthc. 2018;6(2). https://doi.org/10.3390/healthcare6020031.

10. Szebehely M, Trydegård G. Home care for older people in Sweden: a universal model in transition. Health Soc Care Community. 2012;20(3):300-9.

11. Rizzi M, Grassi M, Pecis $M$, et al. A specific home care program improves the survival of patients with chronic obstructive pulmonary disease receiving long term oxygen therapy. Arch Phys Med Rehabil. 2009;90(3):395-401.

12. Braga PP, de SRR, Seixas CT, de CEAB, Andrade AM, Silva YC. Supply and demand in home health care. Cien Saude Colet. 2016;21(3):903-12.

13. Kerber NP d C, Kirchhof ALC, Cezar-Vaz MR. Considerações sobre a atenção domiciliária e suas aproximações com o mundo do trabalho na saúde. Cad Saude Publica. 2008;24:485-93.

14. Facchini LA, Piccini RX, Tomasi E, et al. Avaliação de efetividade da Atenção Básica à Saúde em municípios das regiões Sul e Nordeste do Brasil: contribuições metodológicas. Cad Saude Publica. 2008;24:s159-72.

15. Ministério da Saúde. Portaria Número 825. Brasil: Documentos Ministério da Saúde do Brasil; 2016. http://bvsms.saude.gov.br/bvs/saudelegis/gm/2016/ prt0825_25_04_2016.html. Accessed 5 Feb 2018.

16. Fischer C, Lingsma HF, Marang-van de Mheen PJ, Kringos DS, Klazinga NS. Steyerberg EW. Is the readmission rate a valid quality indicator? A review of the evidence. PLoS One. 2014:9(11):e112282.

17. Hautemanière A, Florentin A, Hartemann P, Hunter PR. Identifying possible deaths associated with nosocomial infection in a hospital by data mining. Am J Infect Control. 2011;39(2):118-22.

18. Vrijens F, Hulstaert F, Devriese S, Van de Sande S. Hospital-acquired infections in Belgian acute-care hospitals: an estimation of their global impact on mortality, length of stay and healthcare costs. Epidemiol Infect. 2012;140(1):126-36.

19. O'Neill J. Antimicrobial resistance: tackling a crisis for the health and wealth of nations. Rev Antimicrob Resist. 2014;1-18.

20. Agência Nacional de Vigilância Sanitária. Boletim de Segurança do Paciente e Qualidade em Serviços de Saúde $n^{\circ}$ 14: Avaliação dos indicadores nacionais das Infecçōes Relacionadas à Assistência à Saúde (IRAS) e Resistência microbiana do ano de 2015. 2016.

21. Punchik B, Komarov R, Gavrikov D, et al. Can home care for homebound patients with chronic heart failure reduce hospitalizations and costs? PLoS One. 2017;12(7):e0182148.

22. Qaseem A, Alguire P, Dallas P, et al. Appropriate use of screening and diagnostic tests to foster high-value, cost-conscious care. Ann Intern Med. 2012;156(2):147-9.

23. Van Walraven C, Naylor CD. Do we know what inappropriate laboratory utilization is?: A systematic review of laboratory clinical audits. Jama. 1998; 280(6):550-8.

24. Capilheira MF, Santos IS. Population-based study of the epidemiology of diagnostic test ordering. Rev Saude Publica. 2006;40(2):289-97.

25. Kobewka DM, Ronksley PE, McKay JA, Forster AJ, van Walraven C. Influence of educational, audit and feedback, system based, and incentive and penalty interventions to reduce laboratory test utilization: a systematic review. Clin Chem Lab Med. 2015;53(2):157-83. https://doi.org/10.1515/ cclm-2014-0778

26. Brasil. Ministério da Saúde. Atenção Domiciliar no SUS: resultados do laboratório de inovação em atenção domiciliar; 2014. p. 184.

27. Diz-Lois PMT, de la Iglesia MF, Nicolás MR, Pellicer VC, Ramos PV, Diz-Lois MF. Predictive factors of unplanned hospital readmission in patients discharged at a short stay medical unit. In: Anales de Medicina Interna (Madrid, Spain: 1984), vol. 19; 2002. p. 221

28. Ricci H, de Araújo MN, Simonetti SH. Readmissão precoce em hospital público de alta complexidade em cardiologia. Northeast Netw Nurs J. 2016; 17(6):828-34.

Ready to submit your research? Choose BMC and benefit from:

- fast, convenient online submission

- thorough peer review by experienced researchers in your field

- rapid publication on acceptance

- support for research data, including large and complex data types

- gold Open Access which fosters wider collaboration and increased citations

- maximum visibility for your research: over $100 \mathrm{M}$ website views per year

At BMC, research is always in progress.

Learn more biomedcentral.com/submissions 